\title{
Molecular Barcoding Reveals the Genus Streptomyces as Associated Root Endophytes of Apple (Malus domestica) Plants Grown in Soils Affected by Apple Replant Disease
}

\author{
Felix Mahnkopp-Dirks, ${ }^{1}$ Viviane Radl, ${ }^{2}$ Susanne Kublik, ${ }^{2}$ Silvia Gschwendtner, ${ }^{2}$ Michael Schloter, ${ }^{2}$ and Traud Winkelmann ${ }^{1, \dagger}$ \\ ${ }^{1}$ Institute of Horticultural Production Systems, Section Woody Plant and Propagation Physiology, Leibniz Universität Hannover, Hanover, \\ Germany \\ ${ }^{2}$ Helmholtz Zentrum München-German Research Center for Environmental Health, Neuherberg, Germany
}

Accepted for publication 13 November 2020.

\section{ABSTRACT}

Apple replant disease (ARD) occurs when apple is repeatedly planted at the same site, leading to growth reductions and losses in fruit yield and quality. Up to now, the etiology has been poorly understood; however, soil (micro)biota are known to be involved. Because endophytes often colonize plants via the rhizosphere, this study aimed at comparing the bacterial endophytic root microbiome in plants growing in ARD-affected and unaffected soils from three different sites based on greenhouse biotests using a molecular barcoding approach. The initial endophytic microbiome of the starting material (in vitro propagated plants of the apple rootstock M26) did not significantly affect the overall richness and diversity of the endophytic community in plants after 8 weeks of growth in the respective soils but some genera of the initial microbiome managed to establish in apple roots. Proteobacteria was the dominant phylum in all samples. No differences in diversity or number of amplicon sequence variants (ASVs) between plants grown in ARD soil and unaffected soil was observed. However, several ASVs of high abundance uniquely found in plants grown in ARD-affected soils were Streptomyces spp. In soil from all three sites, these Streptomyces spp. were negatively correlated with plant growth parameters. Future inoculation experiments using selected Streptomyces isolates have to prove whether bacteria from this genus are opportunists or part of the ARD complex. For the first time, the bacterial endophytic community of apple roots grown in ARD-affected soils was characterized, which will help us to understand the etiology of ARD and develop countermeasures.

Keywords: 16S rRNA amplicon sequencing, Actinobacteria, apple replant disease, endophytes, endophytic microbiome, greenhouse biotest, Malus domestica, microbiome, plants, soils, Streptomyces
Apple replant disease (ARD) is a complex phenomenon which affects apple tree nurseries and orchards worldwide, causing growth reductions and losses in fruit yield and quality (Manici et al. 2013; Mazzola und Manici 2012; Winkelmann et al. 2019). ARD occurs when apple or a closely related species is repeatedly planted at the same site and is described as a "harmfully disturbed physiological and morphological reaction of apple plants to soils that faced

\section{Corresponding author: T. Winkelmann; traud.winkelmann@zier.uni-hannover.de}

Funding: Support was provided by Bundesministerium für Bildung und Forschung grant number FKZ 031B0512. The publication of this article was funded by the Open Access Fund of Leibniz Universität Hannover.

*The $\boldsymbol{e}$-Xtra logo stands for "electronic extra" and indicates that supplementary tables and supplementary figures are published online.

The author(s) declare no conflict of interest. alterations in their (micro-)biome due to previous apple cultures" (Winkelmann et al. 2019). This disease is species specific and can persist for decades (Savory 1966). Because disinfection of the soil leads to better growth, it is generally accepted that biotic factors are the primary cause (Mahnkopp et al. 2018; Mai and Abawi 1981; Yim et al. 2013). Next to fungi belonging to the genera Fusarium, Cylindrocarpon, and Rhizoctonia, a number of other taxa, including oomycetes such as Pythium and Phytophthora spp., nematodes such as Pratylenchus spp., and various bacterial species such as members of the genera Pseudomonas and Bacillus as well as the phylum Actinobacteria, have been reported to contribute to ARD (Čatská et al. 1982; Manici et al. 2017; Mazzola 1998; Otto and Winkler 1993; Tewoldemedhin et al. 2011; Utkhede and Li 1988). However, despite decades of research, the etiology of ARD is still poorly known.

Based on molecular barcoding approaches in the last decade, many studies confirmed not only changes in the abundance of specific pathogens in ARD-affected soils but also significant shifts in the overall structure of the microbiome of the bulk soil and the rhizosphere (Winkelmann et al. 2019). These microbiome shifts 
also affect major functional properties, including the potential to degrade aromatic compounds and functions for biocontrol (Radl et al. 2019).

However, despite their close interaction with host cells, surprisingly, there is still a lack of knowledge of how microbes colonizing the root interior (root endophytes) are affected by ARD. The interior of roots can be colonized mostly by rhizosphere microbiota (e.g., through cracks formed during lateral root emergence and at root tips) (Bulgarelli et al. 2013; Hardoim et al. 2008). Positive effects of endophytes on plants include direct or indirect provision of nutrients (Gaiero et al. 2013; White et al. 2019); production of plant hormones such as auxin, cytokinins, or gibberellins (Hardoim et al. 2015; Santoyo et al. 2016); increased tolerance against abiotic stress (Hardoim et al. 2015); and biocontrol due to competitive mechanisms or production of antimicrobial substances (Haas and Keel 2003). Yet there are also endophytes known for their negative effects on plant health. Some of these facultative pathogens can shift their lifestyle, depending on several factors such as host and endophyte development stage, plant defense reactions, or environmental conditions (Schulz and Boyle 2005). Rosenblueth and Martínez-Romero (2006) put forward the hypothesis of an equilibrium between endophytes and plants that, under certain conditions, gets unbalanced to the detriment of one of the partners.

Only a few studies have investigated the role of endophytes in $\mathrm{ARD}$, focusing on potential fungal root pathogens. Manici et al. (2013) found the root endophytic Cylindrocarpon-like fungi (Ilyonectria and Thelonectria spp.) and Pythium spp. to be main causal agents of growth reduction in the rootstock M9 growing in ARD-affected soil. Cylindrocarpon spp. were also identified next to Rhizoctonia spp. as a pathogenic root endophyte by Kelderer et al. (2012) in row-planted (ARD-affected) and interrowplanted (control) apple trees. In addition, Fusarium solani and $F$. oxysporum were most abundant in roots but not considered pathogenic. Popp et al. (2019) isolated several fungal endophytes from ARD-affected apple roots and reinoculated them in a soil-free biotest. Cadophora, Calonectria, Dactylonectria, Ilyonectria, and Leptosphaeria spp. were reported to have negative effects on plant health. In contrast, studies on the effects of ARD on bacterial root endophytes are scarce. Thus far, only a targeted, cultivationdependent approach has been published, where the focus was on the biocontrol properties of Actinobacteria isolates (mostly belonging to the genus Streptomyces) from the root interior of apple trees. However, no effect was observed when coinoculated to apple seedlings with Pythium irregulare and Cylindrocarpon macrodidymum (Tewoldemedhin et al. 2011).

Therefore, the aim of this study was to investigate the bacterial root endophytic community structure in plants growing in ARDaffected soils compared with ARD-unaffected soils based on greenhouse biotests using a molecular barcoding approach. In these biotests, the ARD-susceptible genotype M26 was planted into ARD-affected soil (untreated or $\gamma$-sterilized) and grass control soil (untreated or $\gamma$-sterilized). To go beyond a local response pattern, we used soils from three different sites from northern Germany in the frame of this study. For generating more robust data, we performed our study in two subsequent years to exclude specific effects of the used soils based on one particular season. We propose that a possible causal agent of ARD should be present in roots from all ARD-affected soils in all three sites.

\section{MATERIALS AND METHODS}

Experimental setting. Soil for these experiments was sampled from three different sites: Heidgraben (x-coordinate 53.699199; y-coordinate 9.683171; WGS 84, Schleswig-Holstein, northern Germany), Ellerhoop (x-coordinate 53.71435; y-coordinate 9.770143; WGS 84, Schleswig-Holstein, northern Germany), and Ruthe (x-coordinate 52.243668; y-coordinate 9.819700; WGS 84, Lower Saxony, Germany). These sites differed in their climatic conditions and soil properties. The upper soil textures of the three sites were defined (based on World Reference Base for soil resources) as sand (Heidgraben), loamy sand (Ellerhoop), and silt loam (Ruthe) (Mahnkopp et al. 2018). Every site contained two different plot variants: (i) ARD plots, where ARD was successfully induced by repeatedly replanting Bittenfelder apple seedlings since 2009 in a 2-year cycle, and (ii) control plots, which were only covered with grass since then. ARD plots in Ruthe and Ellerhoop were replanted for the last time in spring 2015 and in Heidgraben in spring 2016.

Soils were sampled from all three sites at a depth of 0 to $20 \mathrm{~cm}$ at the end of 2015 and 2016. After sampling and sieving $(8 \mathrm{~mm})$, soils were either $\gamma$ irradiated (G) at a minimal dose of $10 \mathrm{kGy}$ or left untreated (UT), resulting in four variants per site: ARD untreated (ARD UT), ARD $\gamma$-irradiated (ARD G), grass untreated (grass UT), and grass $\gamma$-irradiated (grass $\mathrm{G}$ ).

The ARD-susceptible apple rootstock M26, which was propagated and rooted in vitro (Weiß et al. 2017a), was acclimatized for 4 weeks and, afterwards, one plantlet each was planted in 1-liter pots containing the different soil variants. Soils were supplemented with Osmocote Exact 3-4M $(16+9+12+2 \mathrm{MgO}$; https://iclsf.com/de-de/products/ornamental_horticulture/8840-osmocoteexact-standard-3-4m/) at $2 \mathrm{~g} \mathrm{liter}^{-1}$ to exclude nutrient effects. Shoot lengths were measured weekly. Plants were grown for 8 weeks in the greenhouse at a mean daily temperature of $21^{\circ} \mathrm{C}$ and a 16-h photoperiod achieved by additional light (SON-T Philips Master Agro $400 \mathrm{~W}$ ) with a set point of $25 \mathrm{klx}$. Plant protection measures and irrigation were done according to Yim et al. (2015). At the first sign of insect pests, $0.3 \%$ NeemAzal was sprayed. During the night, a sulfur evaporator was used in order to prevent fungal diseases. The greenhouse experiment was conducted twice, in February 2016 and 2017 (Mahnkopp et al. 2018), with nine replicates per variant.

Acclimatized plants (before planting into the soil variants) were treated as described by Mahnkopp et al. (2018) and served as the source for "timepoint zero" (T0) samples in both years.

Sampling. After 8 weeks of cultivation in the greenhouse, 4 representative plants per variant were taken (48 per year, 96 in total) as biological replicates. Roots were washed carefully to get rid of the adhering soil. Shoot and root fresh mass were determined. For surface sterilization, roots were rinsed for $30 \mathrm{~s}$ in $\mathrm{EtOH}(70 \%)$, followed by stirring in $2 \% \mathrm{NaOCl}$ for $7.5 \mathrm{~min}$ and, finally, washing five times in sterile deionized water. The final washing water was plated on 523 medium (Viss et al. 1991) and incubated at room temperature for 1 week. Plating resulted in $<10 \mathrm{CFU} /$ plate in all cases. Roots were stored in sterile 2-ml Eppendorf tubes at $-80^{\circ} \mathrm{C}$ until DNA extraction.

DNA extraction and amplicon sequencing. Surface-sterilized roots (50 to $100 \mathrm{mg} / \mathrm{sample}$ ) were homogenized under frozen conditions using steel beads $(\varnothing 6 \mathrm{~mm}$ ) in a mixer mill (MM400; Retsch, Haan, Germany) with a frequency of $23 \mathrm{~Hz}$ for 2 min using sterilized devices. DNA was extracted using the Invisorb Spin Plant Mini Kit (Stratec, Berlin, Germany) according to the provided protocol. DNA quality was checked using a spectrophotometer (Nanodrop 2000c; Peqlab, Erlangen, Germany).

The primer combination 335F (CADACTCCTACGGGAGGC)/ 769R (ATCCTGTTTGMTMCCCVCRC) (Dorn-In et al. 2015), including overhang adapter sequence, was used to amplify the V3V4 region of the $16 \mathrm{~S}$ ribosomal RNA (rRNA) gene. PCR assays contained $2 \times$ Phusion High-Fidelity Master Mix (1.5 $\mathrm{mM} \mathrm{MgCl}_{2}$, 
$200 \mu \mathrm{M}$ each dNTP, and $0.2 \mathrm{U}$ of Phusion DNA Polymerase [Thermo Fisher Scientific, Waltham, MA, U.S.A.]), 10 pmol of each primer, $5 \mathrm{ng}$ of DNA template, and water to a final volume of $10 \mu \mathrm{l}$. The PCR cycling conditions consisted of an initial denaturation step of $98^{\circ} \mathrm{C}$ for $10 \mathrm{~s}$; followed by 30 cycles involving $1 \mathrm{~s}$ of denaturation at $98^{\circ} \mathrm{C}, 5 \mathrm{~s}$ of annealing at $59^{\circ} \mathrm{C}$, and $45 \mathrm{~s}$ of extension at $72^{\circ} \mathrm{C}$; with a final extension of $1 \mathrm{~min}$ at $72^{\circ} \mathrm{C}$. Triplicate PCR assays were pooled and purified using Agencourt AMPure XP kit (Beckman Coulter, Brea, CA, U.S.A.). The purified products were quantitated using the Quant-IT PicoGreen dsDNA assay kit (Life Technologies Europe, Gent, Belgium). Sample indexing was carried out with Nextera XT Index Kit v2 Set A and B (Illumina, San Diego, CA, U.S.A.) in reaction mixtures containing $10 \mathrm{ng}$ of purified PCR product, $2 \times$ Phusion High-Fidelity Master Mix (1.5 $\mathrm{mM} \mathrm{MgCl}_{2}, 200 \mu \mathrm{M}$ each $\mathrm{dNTP}$, and $0.2 \mathrm{U}$ of Phusion DNA Polymerase [Thermo Fisher Scientific]), 10 pmol of each indexing primer, and water to a final volume of $25 \mu$ l. The indexing PCR cycling conditions consisted of an initial denaturation step of $98^{\circ} \mathrm{C}$ for $30 \mathrm{~s}$; followed by 8 cycles involving $10 \mathrm{~s}$ of denaturation at $98^{\circ} \mathrm{C}, 30 \mathrm{~s}$ of annealing at $55^{\circ} \mathrm{C}$, and $30 \mathrm{~s}$ of extension at $72^{\circ} \mathrm{C}$; with a final extension of $5 \mathrm{~min}$ at $72^{\circ} \mathrm{C}$.

Indexed samples were purified as described above. Equimolar concentrations of the purified indexed samples were prepared and diluted to a final concentration of $4 \mathrm{nM}$. The library was sequenced using the Illumina MiSeq platform with the MiSeq Reagent Kit v3 (600 cycle) (Illumina).

Bioinformatic and statistical analysis. FASTQ files were trimmed with a minimum read length of 50 and a minimum Phred score of 15 using AdapterRemoval (Schubert et al. 2016) without merging forward and reverse reads. Afterward, sequences were analyzed using the QIIME 2 software package release 2017.11 (Caporaso et al. 2010) with default parameters. The QIIME 2 plugin DADA2 (Callahan et al. 2016) was used for quality control with the following parameters: $10 \mathrm{bp}$ were removed n-terminally, and reads were truncated at position 300 (forward) and 260 (reverse) for universal 16S rRNA genes. Expected error was adjusted to 2 .

Taxonomic analysis of the resulting unique amplicon sequence variants (ASVs) was performed using primer-specific pretrained Naive Bayes classifiers of the SILVA_132_QIIME release 99\% and the q2-feature-classifier plugin, setting the confidence threshold to 0.9. Because the PCR-negative control showed no ASVs, contamination during sample processing could be excluded. For further data analysis, unassigned reads and singletons (in sum, $<0.03 \%$ of all reads) were excluded.

Raw sequence data were deposited in GenBank (https://www. ncbi.nlm.nih.gov/genbank/) under the accession PRJNA647245.

$16 \mathrm{~S}$ amplicon sequencing of DNA extracted from the surfacesterilized M26 roots resulted after quality control in a total of $4,132,410$ reads with a mean of 72,498 reads/sample in the biotest in 2016. After removal of chloroplast, archaea, and eukaryotic ASVs, sequence data were rarefied at a number of 28,817 reads (2016). In total, 5,898 ASVs were detected. Because rarefaction analysis (Supplementary Fig. S1) indicated that saturation was reached already with read numbers approximately 5,000 reads/ sample, for 2017, the sequencing effort was reduced, resulting in in total 884,916 reads and a mean of 17,351 reads/sample (rarefied to 4,213 reads/sample after the removal of the chloroplasts). The total number of ASVs was 4,971, which were nearly all covered after rarefying at 4,813 reads/sample (Supplementary Fig. S2). In order to identify identical ASVs between the 2 years, alignments of the sequences of the 2 years on genus level were done using ClustalW Multiple Alignment (Thompson et al. 1994), with number of bootstraps set to 1,000 using BioEdit v7.2.5 (Hall 1999) followed by calculating a sequence differences count matrix. ASVs from 2017 which were $100 \%$ identical to ASVs from 2016 were given the corresponding name of 2016 ASVs to improve comparability of figures and tables.

To calculate the relative abundance, the number of reads per ASV in the samples was divided by the sum of total reads per sample and multiplied by 100 . The relative abundances of ASVs belonging to the same phylum or genus were combined to calculate the overall relative abundance of the corresponding phylum or genus. Species diversity (Shannon and Simpson) and richness (Chao1) indices were determined using the "Phyloseq" (McMurdie and Holmes 2013) and "Vegan" (Oksanen et al. 2019) packages of R v3.6.1 (R Development Core Team 2019) (http://www.R-project.org) and tested for normal distribution based on the Shapiro-Wilk test (Shapiro and Wilk 1965) and homogeneity of variance based on Levene's test (Levene 1960) using the program PAST3 v. 3.20 (Hammer et al. 2001). If the null hypotheses of normal distribution and equal variances were rejected, the Tukey test based on Herberich et al. (2010) was used at $P<0.05$ to determine significant differences of the raw diversity and richness scores. In order to compare the relative abundance of different genera of the initial microbiome (T0 plants) between the years, all ASVs belonging to the same genus were merged. Because of unequal sample size and unequal variance, Welch's two-sample $t$ test was used at $P<0.05$ to determine significant differences. Nonmetric multidimensional scaling (NMDS) was performed with the program PAST3 v. 3.20 (Hammer et al. 2001) using the Bray-Curtis similarity index and analysis of similarity (ANOSIM) in order to visualize the community composition of the different samples. To indicate the influence of the different genera, vectors were added which show the correlation between the corresponding genus and the NMDS score. Spearman's correlation was used in order to correlate ASVs to shoot growth and fresh mass using the program PAST3 v. 3.20 (Hammer et al. 2001). Venn diagrams were designed using the Venn diagram tool of Bioinformatics \& Evolutionary Genomics (http://bioinformatics.psb.ugent.be/webtools/Venn).

To identify specific Streptomyces ASVs, their nucleotide sequences (414 bp) were blasted against the NCBI database (https:// www.ncbi.nlm.nih.gov/) using BLASTn.

\section{RESULTS}

Root and shoot biomass. As expected, in both years, plants grown in untreated ARD-affected soils showed the lowest increase in shoot length and lowest shoot fresh mass in comparison with the other soil variants (Table 1). The $\gamma$ irradiation of grass and ARD soil led to increased shoot length and shoot fresh mass compared with the respective untreated soils. Overall, plants grown in the biotest in 2017 showed a higher biomass in comparison with plants grown in 2016 but the response pattern to the different soils variants was comparable between both years. Detailed growth data for the full set of nine plants per variant can be found in Mahnkopp et al. (2018) whereas, in Table 1, only the data of the plants selected for the barcoding approach of this study are presented.

Endophytic bacterial community composition and diversity in plant roots grown in different soil variants. The mean number of observed ASVs per sample was 244 in 2016 (Table 2) and 201 in 2017 (Table 3). The highest number of observed ASVs were found in plants grown in ARD G soil from Ellerhoop $(n=339 \pm 93)$ and the lowest number in the variant Heidgraben ARD G $(n=148 \pm 62)$ 
(both in 2016). In both years, no significant differences in diversity or richness indices were recorded within or between the sites (Tukey's test, $P<0.05$ ).

Proteobacteria was clearly the dominant phylum in all variants, with relative abundance ranging from $66.9 \%$ (Heidgraben ARD G) to $83.7 \%$ (Ruthe grass UT) (Supplementary Fig. S3) for the biotest performed in 2016. Phylum Bacteroidetes was of second most abundance, with a mean value of $10.3 \%$, followed by Actinobacteria (5\%) and Firmicutes (4.4\%). Members of Actinobacteria appeared in higher relative abundance in roots grown in ARD UT compared with the other variants of the respective site. The strongest difference was observed in Heidgraben, where the abundance of ASVs linked to Actinobacteria in ARD UT variants $(15.60 \%)$ was significantly higher than in ARD G $(5.03 \%)$, grass UT $(2.75 \%)$, and grass $\mathrm{G}$ variants $(3.47 \%)$. The second biotest in
2017 showed similar shares for the different phyla (Supplementary Fig. S4). ASVs assigned to Proteobacteria ranging from 66.7 to $89.3 \%$ were dominant, followed by Bacteroidetes, with a mean value of $13.6 \%$ relative abundance; Actinobacteria, with $8.1 \%$; and Firmicutes, with $2.2 \%$. However, the higher abundance of ASVs linked to phylum Actinobacteria in the untreated ARD variants was not observed in this year.

Dynamics of endophytic bacteria during the biotest. T0 plants of 2016 had the highest diversity of all treatments over the years (Table 2). In 2017, T0 plants showed a significantly lower diversity compared with 2016 T0 plants (Supplementary Fig. S8). After cultivation for 8 weeks in the different soils, 9 of 12 variants of 2016 still had higher numbers in the observed ASVs compared with 2017. However, these differences were not significant (Supplementary Fig. S8).

TABLE 1

Shoot fresh mass and increase of shoot length of M26 apple plants grown for 8 weeks in the greenhouse biotest in 2016 and $2017^{y}$

\begin{tabular}{|c|c|c|c|c|c|c|c|c|c|c|c|c|}
\hline \multirow[b]{3}{*}{ Year $^{z}$} & \multicolumn{4}{|c|}{ Heidgraben } & \multicolumn{4}{|c|}{ Ellerhoop } & \multicolumn{4}{|c|}{ Ruthe } \\
\hline & \multicolumn{2}{|c|}{ ARD } & \multicolumn{2}{|c|}{ Grass } & \multicolumn{2}{|c|}{ ARD } & \multicolumn{2}{|c|}{ Grass } & \multicolumn{2}{|c|}{ ARD } & \multicolumn{2}{|c|}{ Grass } \\
\hline & UT & $G$ & UT & $G$ & UT & $\mathrm{G}$ & UT & $G$ & UT & $\mathrm{G}$ & UT & $\mathrm{G}$ \\
\hline \multicolumn{13}{|l|}{2016} \\
\hline Length $(\mathrm{cm})$ & $5.9 \pm 2.3 a$ & $18.5 \pm 1.5 \mathrm{c}$ & $13.5 \pm 2 b$ & $27.7 \pm 6.3 c$ & $7.5 \pm 1 \mathrm{a}$ & $12.4 \pm 3.8 \mathrm{ab}$ & $19.6 \pm 1.6 b$ & $25.9 \pm 1.7 \mathrm{c}$ & $8.5 \pm 1.4 \mathrm{a}$ & $25.2 \pm 0.2 \mathrm{c}$ & $16.7 \pm 1.9 \mathrm{~b}$ & $32.0 \pm 1.4 \mathrm{~d}$ \\
\hline Mass (g) & $2.8 \pm 0.6 \mathrm{a}$ & $7.2 \pm 0.6 b$ & $5.9 \pm 0.6 b$ & $10.7 \pm 1 \mathrm{c}$ & $3.2 \pm 0.7 \mathrm{a}$ & $5.9 \pm 1.3 \mathrm{ab}$ & $7.4 \pm 1.1 \mathrm{~b}$ & $14.4 \pm 0.8 \mathrm{c}$ & $3.7 \pm 0.4 \mathrm{a}$ & $11.4 \pm 1 \mathrm{c}$ & $7.1 \pm 0.1 \mathrm{~b}$ & $17.6 \pm 2.3 d$ \\
\hline \multicolumn{13}{|l|}{2017} \\
\hline Length $(\mathrm{cm})$ & $5.7 \pm 2.2 \mathrm{a}$ & $31.7 \pm 1.3 b$ & $29.8 \pm 3.4 b$ & $42.3 \pm 3.9 \mathrm{c}$ & $13.4 \pm 3.4 \mathrm{a}$ & $24.7 \pm 0.8 b$ & $31.6 \pm 3.8 \mathrm{bc}$ & $43.0 \pm 4.9 c$ & $22.9 \pm 1.9 \mathrm{a}$ & $34.3 \pm 1.5 b$ & $36.3 \pm 4.9 \mathrm{bc}$ & $41.6 \pm 1.7 \mathrm{c}$ \\
\hline Mass (g) & $2.8 \pm 0.6 a$ & $11.7 \pm 0.7 \mathrm{bc}$ & $9.4 \pm 1.2 b$ & $19.8 \pm 3.9 \mathrm{c}$ & $4.8 \pm 0.9 a$ & $9.4 \pm 0.3 b$ & $9.7 \pm 1.9 \mathrm{~b}$ & $18.7 \pm 3.6 \mathrm{~b}$ & $8.3 \pm 1.1 \mathrm{a}$ & $12.8 \pm 1.4 \mathrm{~b}$ & $11.8 \pm 2.1 \mathrm{ab}$ & $15.9 \pm 1 b$ \\
\hline
\end{tabular}

y Surface-sterilized roots of these plants were used for DNA extraction and amplicon sequencing. ARD $=$ apple replant disease, UT = untreated, and $\mathrm{G}=\gamma$ irradiated. Shown is the mean and the standard deviation of $n$ plants. Different letters indicate significant differences within the sites (Tukey's test, $P \leq 0.05$ ).

z Year and parameter: Length $=$ increase in shoot length and Mass $=$ shoot fresh mass.

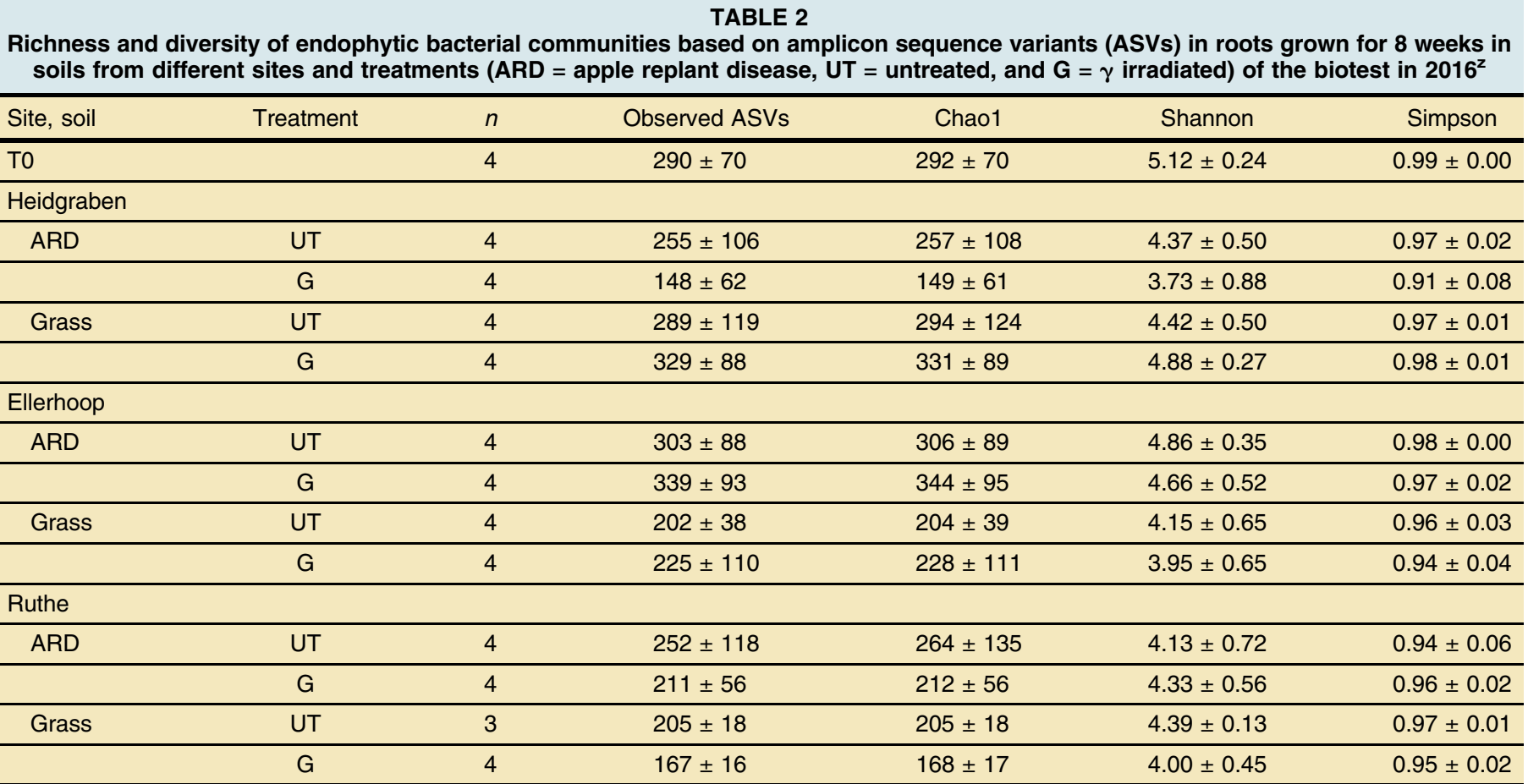

z Additionally, acclimatized plants at timepoint zero (T0) before transferring into the soil variants are shown. There was no significant difference within and between the sites according to Tukey's test at $P \leq 0.05$. Shown are mean \pm standard deviation of $n$ replicates. 
On the phylum level, T0 plants grown in 2016 were dominated by Proteobacteria (79\%, Supplementary Fig. S3), which did not change after 8 weeks of cultivation in the different soils. In 2017 , this value increased to $89 \%$ for T0 plants but, here, this high relative abundance was found reduced by approximately $16 \%$ after the plants had been grown for 8 weeks in the different soil variants, regardless of the soil (Supplementary Fig. S4).

On higher phylogenetic levels, proteobacterial groups of the genera Shewanella and Halomonas belonged to the top three genera regarding relative abundance in T0 plants in both years (Supplementary Table S2). However, in total, nearly one-third (31.9\%) of the genera showed significant differences in abundance between the years. In T0 plants from 2016, for example, Ralstonia was (with 6.6\%) the most abundant genus but was not present in 2017 T0 plants. Even after growing for 8 weeks in different soils, this abundance pattern still remained for ASVs linked to Ralstonia. Similar contrasting abundance patterns were observed for genus Pseudomonas when both years were compared. Here, we could link $12.6 \%$ of all ASVs from T0 plants to this genus in 2017, which was more than four times higher than in 2016. However, in contrast to ASVs linked to Ralstonia, after 8 weeks of cultivation in the different soils, these initial differences in abundance of Pseudomonas were no longer detectable.

To analyze $\beta$-diversity, three-dimensional nonmetric multidimensional scalings were created for the untreated soils. In general, high variability within variants could be observed. In both years, T0 plants significantly separated from the other variants (ANOSIM with $P \leq 0.05$ ) (Fig. 1; Supplementary Fig. S5). Only for the biotest in 2016, significant differences between other variants were observed, especially for the treatments with soil from Ruthe (Fig. 1). ASVs assigned to genera Pseudomonas, Rhizobium, and especially Streptomyces were closely linked with ARD, whereas ASVs related to Rhodanobacter, Dyella, Bradyrhizobium, Sphingomonas, and Rhizomicrobium pointed to the untreated grass variants (Fig. 1). Most responsible for differentiation of T0 were ASVs which were linked to genera Halomonas, Acinetobacter, and Shewanella. In the biotest in 2017, no clear clustering except for T0 was observed (Supplementary Fig. S5).

Identification of bacterial responders in the different treatments and correlation with plant growth. To further investigate ASVs responding to the different treatments of each site, Venn diagrams were designed. On the one hand, the number of ASVs shared by all four different variants per site, which we considered as the core microbiome of a given site, was surprisingly small. In 2016, only six ASVs (relative abundance $>0.5 \%$ ) in soil variants from Heidgraben, three in those from Ellerhoop, and four in those from Ruthe were present in all variants (Fig. 2). In 2017, these numbers were reduced to zero (Heidgraben), two (Ellerhoop), and one (Ruthe) (Fig. 3). On the other hand, the number of ASVs which were unique for each variant was high. In 2016, unique ASVs in untreated ARD variants ranged from 15 for Ruthe and 19 for Heidgraben to 28 for Ellerhoop (Fig. 2). In the untreated grass variants, the number of unique ASVs ranged from 23 for Ruthe to 26 for Ellerhoop and 29 for Heidgraben. Although the overall distribution was very similar in both years, for the soil from Ellerhoop, some variations were observed: the number of unique ASVs changed in untreated grass variants from 26 in 2016 to 9 in 2017. Results for soil variants from Heidgraben showed the lowest variation between the years, except for the unique ASVs for the grass variant sterilized by $\gamma$-irradiation, where 16 (2016) and 31 (2017) unique ASVs were observed.

In order to identify responders toward ARD, the unique ASVs of the untreated ARD variants were correlated with shoot growth and fresh mass of all variants of the three sites. In 2016, most noticeable were ASVs related to the genus Streptomyces (Fig. 2), which closely linked to plants grown in ARD-affected soils, confirming the overall observation that ASVs related to Actinobacteria were positively responding to the ARD-affected soils with increased levels in relative abundance. In Heidgraben ARD UT, 7 of 19 unique ASVs were linked to the genus Streptomyces, followed by

TABLE 3

Richness and diversity of endophytic bacterial communities based on amplicon sequence variants (ASVs) in roots grown for 8 weeks in soils from different sites and treatments $\left(A R D=\right.$ apple replant disease, UT = untreated, and $G=\gamma$ irradiated) of the biotest in $2017^{z}$

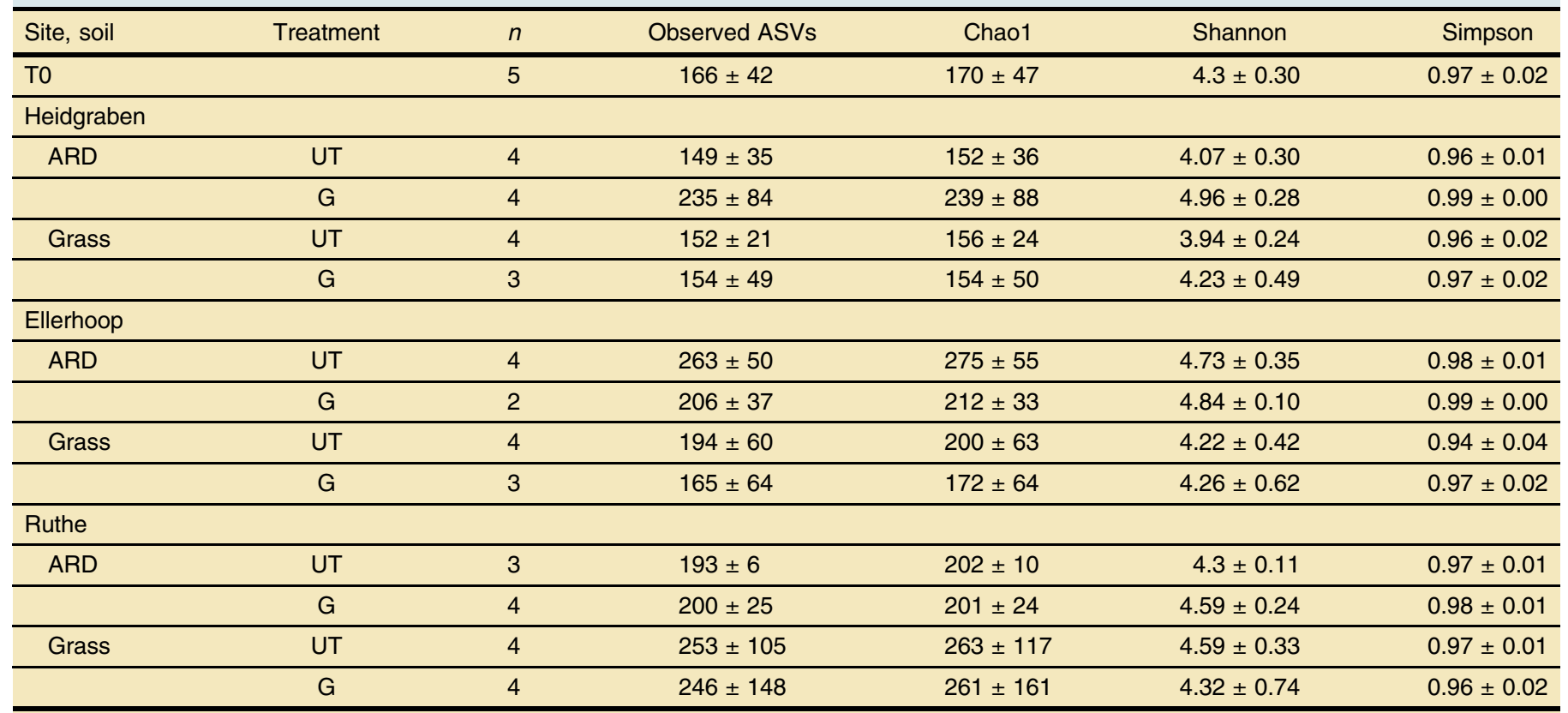

z Additionally, acclimatized plants at timepoint zero (T0) plants before transferring into the soil variants are shown. There was no significant difference within and between the sites according to Tukey's test at $P \leq 0.05$. Shown are mean \pm standard deviation of $n$ replicates. 
Ellerhoop ARD UT (4 of 28) and Ruthe ARD UT (3 of 15). Most of these ASVs were high in relative abundance. Streptomyces ASV66 in Heidgraben and Streptomyces ASV42 in Ruthe showed the highest relative abundance, with 4.48 and $4.10 \%$, respectively. All Streptomyces ASVs were negatively correlated with the increase of shoot length and shoot fresh mass and some of them were even present in at least two sites. Streptomyces ASV21, which was present in all three sites as a unique ASV, showed the second highest negative correlation with both plant growth parameters ( -0.54 and -0.58 , respectively). This number was only surpassed by Streptomyces ASV70 and Streptomyces ASV76 (both present in Heidgraben and Ellerhoop), with a correlation of -0.59 to the increase of shoot length and -0.65 to shoot fresh mass.

A high number of other genera harboring unique ASVs were also negatively correlated with plant growth parameters. For example, Novosphingobium ASV92 and Neorhizobium ASV47 (highly abundant in Heidgraben and Ellerhoop) negatively correlated with increase of shoot length $(-0.59$ and -0.53 , respectively) and shoot fresh mass ( -0.53 and -0.59 , respectively) (Fig. 2).

In 2017, the overall number of negatively correlated ASVs was lower (Fig. 3). Nevertheless, several Streptomyces ASVs (also present in at least two sites) again were negatively correlated with plant growth. In Heidgraben and Ellerhoop, the relative abundance of Streptomyces ASV76 and Streptomyces ASV621 showed a correlation of -0.53 and -0.57 to increase of shoot length and -0.60 and 0.61 to shoot fresh mass, respectively.

We were further interested in unique ASVs of the untreated grass variants to identify possible plant-growth-promoting bacteria (PGPB), which could help to counteract ARD. In 2016, several ASVs of different genera were present in more than two sites (Supplementary Fig. S6). These included ASVs related to genera Dyella, Massilia, Rhizobium, Rhodanobacter, and unclassified species of family Moraxellaceae. In the biotest 2017, only two ASVs (assigned to genera Rhizobium and Sphingobium) were

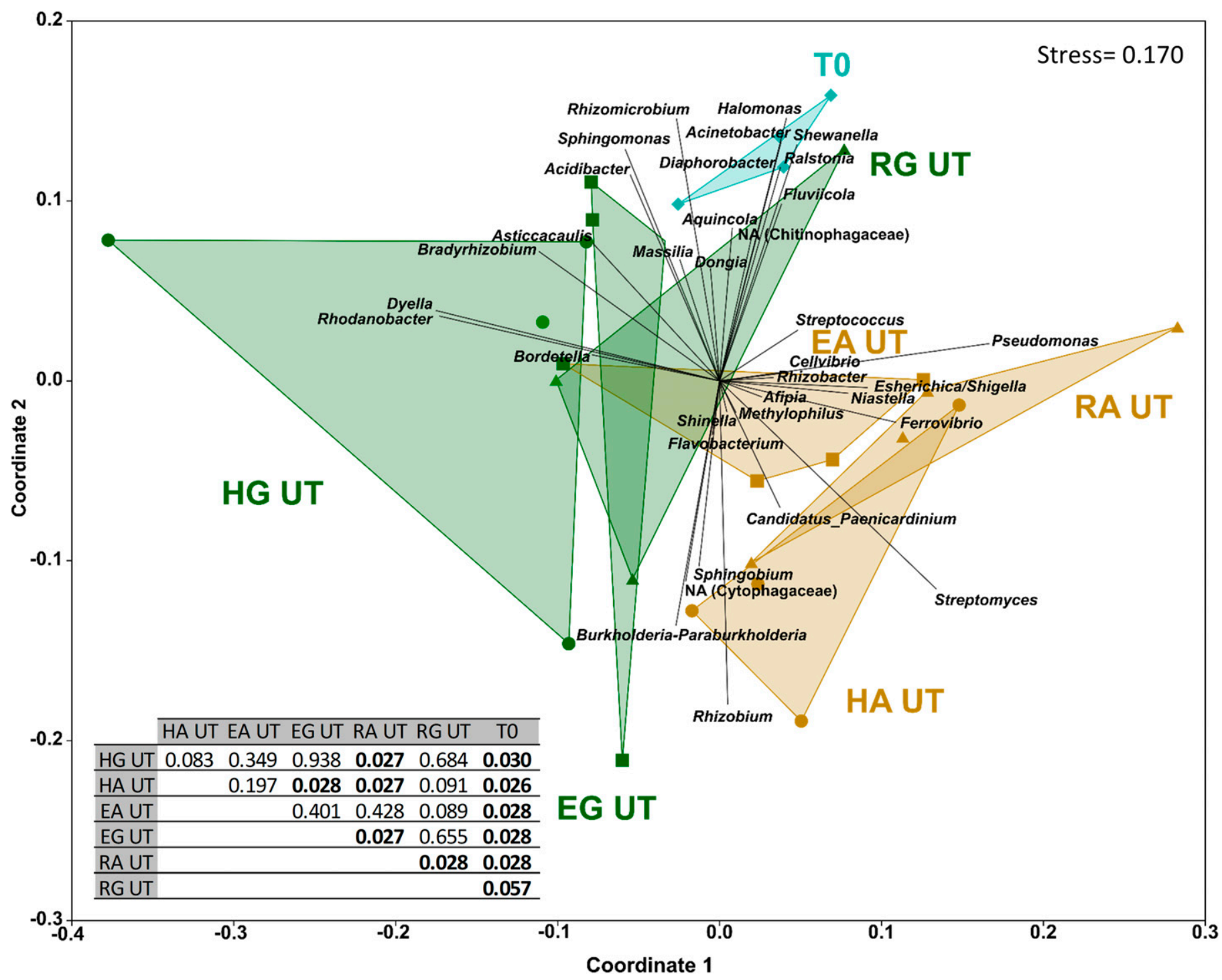

Fig. 1. Three-dimensional nonmetric multidimensional scaling (NMDS) using Bray-Curtis dissimilarity of roots grown for 8 weeks in soils from different sites of the biotest in 2016. The $\gamma$-irradiated variants are not included. Vectors represent the correlation coefficient between the corresponding genus and the NMDS score. Relative lengths and the directions of the vectors indicate the influence of the respective genera (RA $>1 \%)$. The third axis is not shown. Results of the one-way analysis of similarities are shown in the lower left corner, and significant differences are highlighted in bold $(P \leq 0.05)$. $H=$ Heidgraben, $\mathrm{E}=$ Ellerhoop, $\mathrm{R}=$ Ruthe $\mathrm{A}=$ apple replant disease, $\mathrm{G}=$ grass, and $\mathrm{UT}=$ untreated . 
present at at least at two sites (Supplementary Fig. S7) However, none of them showed positive correlations with plant growth. The only positively correlated ASV was related to unclassified members of family Rhizobiaceae and found in 2017 with a relative abundance of $0.95 \%$ and a correlation of 0.32 and 0.30 to shoot growth and shoot fresh mass, respectively (Supplementary Fig. S7).

\section{DISCUSSION}

In the present study, we characterized the bacterial root endophytic community of apple plants grown in replant and nonreplant soil in order to understand the etiology of ARD and develop countermeasures.

Endophytic bacterial communities in apple roots were dominated by Proteobacteria. Proteobacteria was the dominant phylum in most studies where bulk soil or rhizosphere samples from ARD-affected sites had been analyzed (Franke-Whittle et al. 2015; Peruzzi et al. 2017; Sun et al. 2014; Tilston et al. 2018; Yim et al. 2015), with an average relative abundance of $35 \%$ (Nicola et al. 2018). The same was true for the root endophytes analyzed in our experiments in both years (Supplementary Figs. S3 and S4). However, in comparison with Nicola et al. (2018), the relative abundance of Proteobacteria in roots from plants grown in ARD UT was clearly higher (76\% in 2016 and $71 \%$ in 2017 in an average of all three sites). This enrichment of Proteobacteria in the endosphere could be explained by selective recruitment or colonization or a higher competitiveness inside the plant. Members of this phylum are known for their various secretion systems (Preston et al. 2005), their fast growth, and their high metabolic activity and, therefore, they mostly predominate the endosphere (Lundberg et al. 2012; Reinhold-Hurek et al. 2015).
Heidgraben

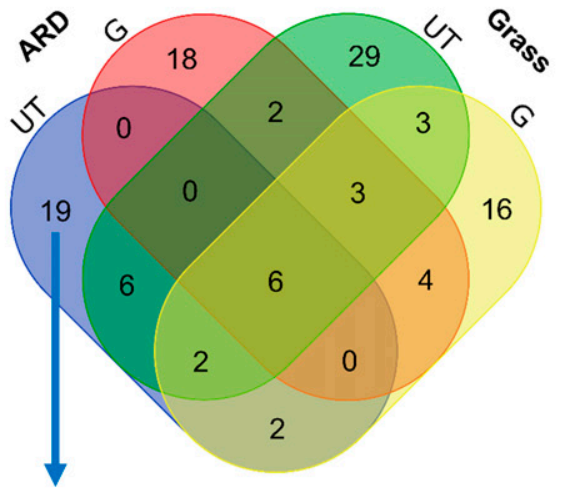

\begin{tabular}{lccc}
\hline Heidgraben ARD UT & \multicolumn{3}{c}{$\begin{array}{c}\text { Spearman } \\
\text { correlation }\end{array}$} \\
\hline ASV & RA (\%) & $\begin{array}{c}\text { Shoot } \\
\text { growth }\end{array}$ & $\begin{array}{c}\text { Shoot } \\
\text { FM }\end{array}$ \\
\hline Candidatus_Paenicardinium & 1.86 & -0.56 & -0.56 \\
ASV112 & 0.59 & & \\
\hline Cellvibrio_ASV77 & 0.94 & & \\
\hline Lysobacter_ASV120 & 0.56 & & \\
\hline Methylotenera_ASV209 & 0.73 & -0.53 & -0.59 \\
\hline Neorhizobium_ASV47 & 3.98 & & \\
\hline Novosphingobium_ASV29 & 3.98 & -0.59 & -0.53 \\
\hline Novosphingobium_ASV92 & 0.82 & & \\
\hline Rhizobium_ASV175 & 0.73 & & \\
\hline Rhizobium_ASV31 & 0.52 & & \\
\hline Rhodanobacter_ASV46 & 0.62 & -0.34 & -0.40 \\
\hline Simplicispira_ASV289 & 1.07 & & -0.30 \\
\hline Sphingobium_ASV20 & 0.53 & -0.47 & -0.47 \\
\hline Streptomyces_ASV121 & 0.53 & -0.54 & -0.58 \\
\hline Streptomyces_ASV21 & 1.20 & -0.53 & -0.54 \\
\hline Streptomyces_ASV43 & 4.48 & -0.43 & -0.43 \\
\hline Streptomyces_ASV66 & 1.27 & -0.59 & -0.65 \\
\hline Streptomyces_ASV70 & 2.28 & -0.53 & -0.52 \\
\hline Streptomyces_ASV71 & 1.08 & -0.59 & -0.65 \\
\hline Streptomyces_ASV76 & & & \\
\hline & & & \\
\hline
\end{tabular}

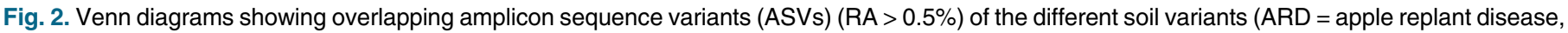
grass, UT = untreated, and G = $\gamma$ irradiated) from Heidgraben, Ellerhoop, and Ruthe for the biotest in 2016 . The three tables show the site-specific unique ASVs of ARD UT variants with their relative abundance and Spearman correlation with shoot growth (= increase in shoot length) and fresh mass (only significant correlations are shown; $P \leq 0.05$ ). ASVs highlighted in bold appear in at least two sites.

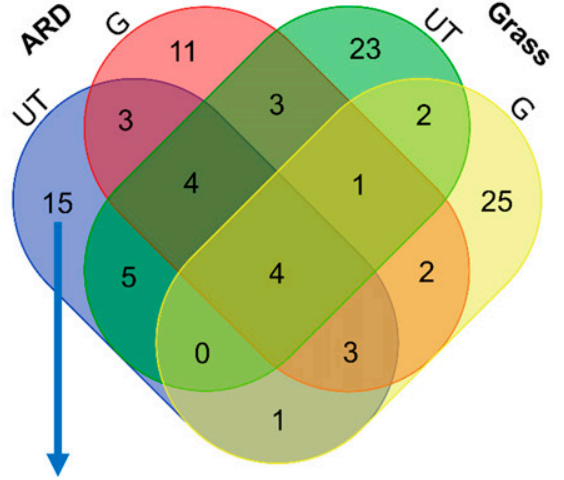

\begin{tabular}{lccc}
\hline Ellerhoop ARD UT & \multicolumn{3}{c}{$\begin{array}{c}\text { Spearman } \\
\text { correlation }\end{array}$} \\
\hline ASV & RA (\%) & $\begin{array}{c}\text { Shoot } \\
\text { growth }\end{array}$ & $\begin{array}{c}\text { Shoot } \\
\text { FM }\end{array}$ \\
\hline Asticcacaulis_ASV56 & 0.68 & & \\
\hline $\begin{array}{l}\text { Burkholderia-Paraburkholderia } \\
\text { ASV159 }\end{array}$ & 0.75 & -0.37 & -0.37 \\
\hline Cellvibrio_ASV335 & 0.55 & & \\
\hline Ferrovibrio_ASV142 & 0.64 & & \\
\hline Flavobacterium_ASV15 & 2.08 & & \\
\hline Flavobacterium_ASV84 & 0.67 & & -0.33 \\
\hline Hydrogenophaga_ASV542 & 0.52 & -0.37 & -0.33 \\
\hline Massilia_ASV158 & 0.69 & & \\
\hline Methylobacillus_ASV214 & 0.58 & -0.31 & -0.30 \\
\hline Methylophilus_ASV108 & 0.53 & & -0.30 \\
\hline Methylophilus_ASV303 & 0.58 & -0.38 & -0.45 \\
\hline NA_ASV161 (Rhodospirillaceae) & 0.91 & -0.36 & \\
\hline Neorhizobium_ASV47 & 0.93 & -0.53 & -0.59 \\
\hline Novosphingobium_ASV92 & 0.82 & -0.59 & -0.53 \\
\hline Pedobacter_ASV218 & 0.94 & & \\
\hline Pseudomonas_ASV13 & 1.37 & -0.50 & -0.49 \\
\hline Pseudomonas_ASV2 & 2.00 & -0.43 & -0.47 \\
\hline Pseudomonas_ASV332 & 0.71 & & \\
\hline Pseudomonas_ASV38 & 2.46 & & \\
\hline Pseudomonas_ASV52 & 1.12 & -0.34 & -0.30 \\
\hline Pseudomonas_ASV591 & 0.67 & & \\
\hline Rhizobium_ASV12 & 2.12 & -0.33 & -0.31 \\
\hline Rhizobium_ASV33 & 1.28 & -0.29 & -0.36 \\
\hline Rhizobium_ASV62 & 0.65 & & \\
\hline Streptomyces_ASV21 & 2.55 & -0.54 & -0.58 \\
\hline Streptomyces_ASV322 & 0.64 & -0.41 & -0.41 \\
\hline Streptomyces_ASV70 & 1.03 & -0.59 & -0.65 \\
\hline Streptomyces_ASV76 & 1.14 & -0.59 & -0.65 \\
\hline & & & \\
\hline
\end{tabular}


In many studies where rhizosphere and bulk soil samples of ARD-affected sites have been analyzed, Actinobacteria was among the most abundant phyla, with an average relative abundance of $16 \%$ (Nicola et al. 2018), which was slightly higher than in our study when we focused on root endophytes (10 and 11\% in 2016 and 2017, respectively). In other studies, Bacteroidetes showed an average relative abundance of $14 \%$ (Nicola et al. 2018) and $13 \%$ (Tilston et al. 2018). In our study, values ranged between 8\% (2016) and 15\% (2017). As expected, members of Acidobacteria, which were also highly abundant in the rhizosphere and bulk soil in the abovementioned studies, were low in relative abundance in the root interior, due to the ecophysiological properties of these bacteria, including the use of complex organic compounds and their slow growth.

Differences between the outcome of the biotest of 2016 and 2017. Significant differences occurred in the results comparing biotests between 2016 and 2017. In 2016, Actinobacteria were significantly higher in relative abundance in root samples from ARD UT compared with the grass or $\gamma$-sterilized variants (Supplementary Fig. S3). Surprisingly, this was not the case in 2017 (Supplementary Fig. S4). Furthermore, there was a clustering of
ARD variants apart from the grass variants in 2016 (Fig. 1) but not in 2017 (Supplementary Fig. S5). These differences in the outcome of the biotests could be due to various factors (e.g., higher shoot lengths of T0 plants of 2017 or variation in environmental factors). Another reason could be related to the soil. First of all, soil collection might have resulted in samples of different microbial composition due to patchy appearance of ARD in the field (Simon et al. 2020). Furthermore, at our reference sites, replanting takes place every second year, and was carried out in 2015 and 2017 at Ruthe and Ellerhoop and in 2014 and 2016 at Heidgraben. Soil for the first greenhouse experiment in 2016 was sampled at the end of 2015, where plants at Ruthe and Ellerhoop had been replanted for the fourth time in spring 2015, whereas plants in Heidgraben had just been uprooted. For the experiment in 2017, soil was collected at the end of 2016, when plants at Ellerhoop and Ruthe had been uprooted and at Heidgraben had been replanted for the fifth time in spring. It is known that the microbial community composition in the rhizosphere of different apple genotypes varies seasonally and among years (Rumberger et al. 2007). Also, replanting is known to have an influence of the rhizosphere community composition (Sun et al. 2014).
Heidgraben

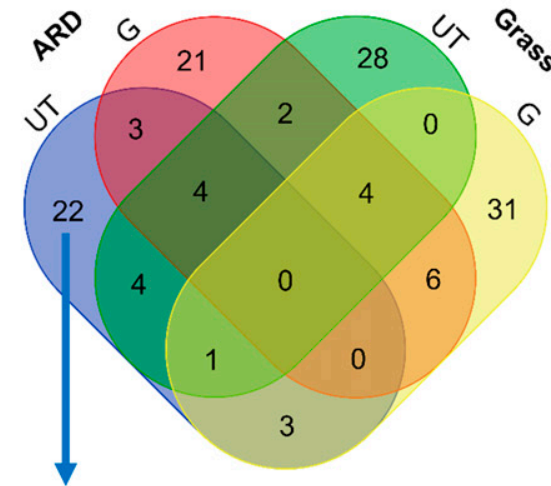

\begin{tabular}{lccc}
\hline Heidgraben ARD UT & \multicolumn{3}{c}{$\begin{array}{c}\text { Spearman } \\
\text { correlation }\end{array}$} \\
\hline ASV & RA (\%) & $\begin{array}{c}\text { Shoot } \\
\text { growth }\end{array}$ & $\begin{array}{c}\text { Shoot } \\
\text { FM }\end{array}$ \\
\hline Bordetella_ASV6403 & 1.03 & & -0.32 \\
\hline Burkholderia-Paraburkholderia_ASV6424 & 1.06 & \\
\hline Burkholderia-Paraburkholderia_ASV6476 & 1.55 & \\
\hline Burkholderia-Paraburkholderia_ASV6481 & 1.37 & \\
\hline Burkholderia-Paraburkholderia_ASV6501 & 0.90 & & \\
\hline Burkholderia-Paraburkholderia_ASV6525 & 3.16 & & \\
\hline Chitinophaga_ASV855 & 3.76 & & \\
\hline Chitinophaga_ASV858 & 3.30 & & \\
\hline Chitinophaga_ASV297 & 1.96 & -0.34 & -0.34 \\
\hline Dyella_ASV255 & 2.47 & & \\
\hline Labrys_ASV4559 & 0.53 & & \\
\hline NA_ASV4764 (Rhizobiaceae) & 0.61 & -0.47 & -0.50 \\
\hline NA_ASV8160 (Enterobacteriaceae) & 1.00 & -0.48 & -0.49 \\
\hline NA_ASV8179 (Enterobacteriaceae) & 0.80 & -0.45 & -0.44 \\
\hline NA_ASV8190 (Enterobacteriaceae) & 0.71 & & \\
\hline NA_ASV9489 (Rhodanobacteraceae) & 1.89 & & \\
\hline Rhizobium_ASV4589 & 0.57 & & \\
\hline Rhodanobacter_ASV9389 & 0.55 & & \\
\hline Rhodanobacter_ASV9398 & 0.56 & & \\
\hline Streptomyces_ASV76 & 0.61 & -0.53 & -0.60 \\
\hline Streptomyces_ASV621 & 0.58 & -0.57 & -0.61 \\
\hline Streptomyces_ASV121 & 0.61 & -0.35 & -0.34 \\
\hline & & & \\
\hline
\end{tabular}

Ellerhoop

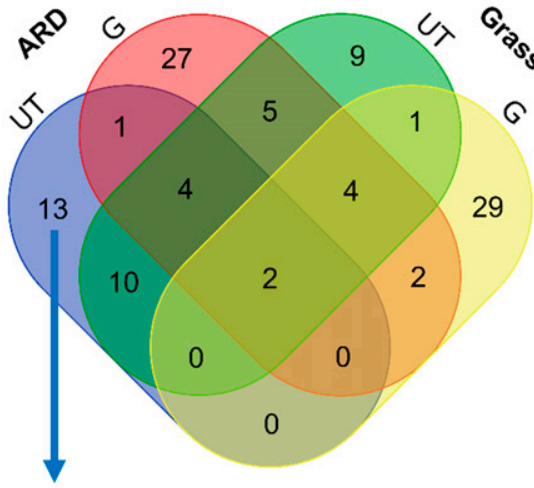

\begin{tabular}{lcccc}
\hline Ellerhoop ARD UT & \multicolumn{4}{c}{$\begin{array}{c}\text { Spearman } \\
\text { correlation }\end{array}$} \\
\hline ASV & $\begin{array}{c}\text { RA } \\
\text { (\%) }\end{array}$ & $\begin{array}{c}\text { Shoot } \\
\text { growth }\end{array}$ & $\begin{array}{c}\text { Shoot } \\
\text { FM }\end{array}$ \\
\hline Asticcacaulis_ASV3687 & 1.22 & & \\
\hline Burkholderia- & 0.99 & & \\
Paraburkholderia_ASV26 & 0.69 & -0.33 & -0.39 \\
\hline Flavobacterium_ASV1140 & 0.78 & & \\
\hline Methylophilus_ASV7461 & 0.63 & & \\
\hline Methylophilus_ASV7465 & 1.07 & -0.48 & -0.49 \\
\hline NA_ASV8160 (Enterobacteriaceae) & 0.56 & -0.34 & -0.38 \\
\hline Pseudoxanthomonas_ASV9569 & 0.93 & & \\
\hline Rhodanobacter_ASV9396 & 1.93 & & \\
\hline Sphingobium_ASV5334 & 2.09 & & \\
\hline Sphingobium_ASV199 & 0.84 & -0.36 & -0.39 \\
\hline Streptomyces_ASV607 & 0.59 & & \\
\hline Streptomyces_ASV611 & 0.60 & -0.35 & -0.34 \\
\hline Streptomyces_ASV121 & & & \\
\hline & & &
\end{tabular}
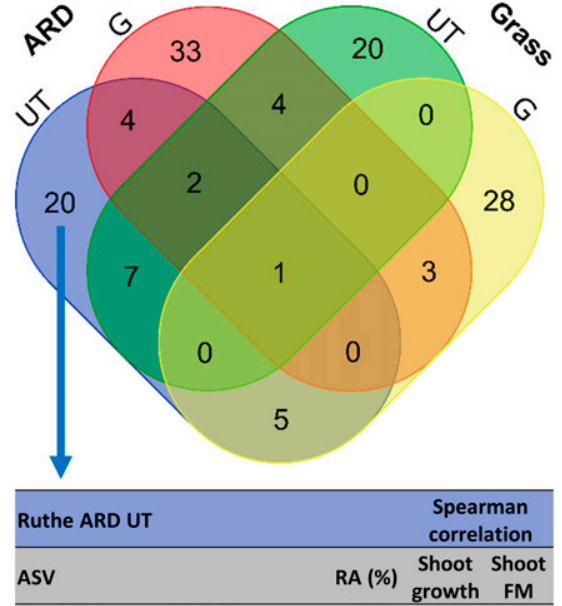

\begin{tabular}{lll}
\hline Arachidicoccus_ASV837 & 1.31 & -0.35 \\
\hline
\end{tabular} Arachidicoccus_ASV839 0.94 Arachidicoccus_ASV840 0.58 Bordetella_ASV6403 $\quad 0.65 \quad-0.32$ Burkholderia-

Paraburkholderia ASV6501 0.66

Cellvibrio_ASV7794 2.06

Dyella_ASV255 0.97

Methylobacillus_ASV7450 0.56

\begin{tabular}{ll}
\hline NA_ASV5005 & 0.59 \\
(Xanthobacteraceae) &
\end{tabular}

\begin{tabular}{ll}
\hline NA_ASV9489 & 0.76 \\
(Rhodanobacteraceae) & 0.76
\end{tabular}

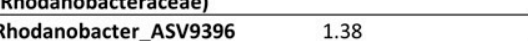

\begin{tabular}{llll} 
Rhodanobacter_ASV338 & 0.86 & -0.33 & -0.33 \\
\hline
\end{tabular}

Rhodanobacter_ASV9402 1.07

Rhodanobacter_ASV9404 0.66

Rhodanobacter_ASV9410 0.78

\begin{tabular}{llll}
\hline Streptomyces_ASV76 & 3.14 & -0.53 & -0.60 \\
\hline
\end{tabular}

\begin{tabular}{llll}
\hline Streptomyces_ASV21 & 2.18 & -0.55 & -0.63 \\
\hline
\end{tabular}

Streptomyces_ASV621 $\quad 2.12 \quad-0.57 \quad-0.61$ Wolbachia_ASV5191

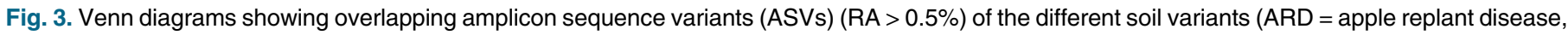
grass, UT = untreated, and G = $\gamma$ irradiated) from Heidgraben, Ellerhoop, and Ruthe for the biotest in 2017 . The three tables show the site-specific unique ASVs of ARD UT variants with their relative abundance and Spearman correlation with shoot growth (= increase in shoot length) and fresh mass (only significant correlations are shown; $P \leq 0.05$ ). ASVs highlighted in bold appear in at least two sites. 
Another reason for these different outcomes of the biotest in the 2 years could be differences in the initial endophytic bacterial community composition of the starting material (T0) plants. In this study, a higher diversity and number of ASVs of the initial microbiome in the plant roots was found in 2016 compared with that in 2017. However, this difference between the 2 years was not significant after 8 weeks of growth in the soil. Therefore, a higher diversity and number of ASVs of the initial microbiome did not lead to higher number of ASVs and diversity in plant roots after 8 weeks of growth in the soil. Because soil is the main reservoir of microorganisms for the plant microbiome (Berg and Smalla 2009; Bonito et al. 2014; Hartman and Tringe 2019; Lareen et al. 2016), it is one of the major factors influencing the number of ASVs and diversity. However, some genera (e.g., Ralstonia) were present in the 2017 T0 plants and were still present in the plant roots after growth for 8 weeks in the soil (Supplementary Table S2). With this in mind, one strategy to help to overcome ARD could be to inoculate apple plants with PGPB before transferring them into the soil. This so-called microbiome engineering of plants was recently reviewed by Orozco-Mosqueda et al. (2018). Johnston-Monje and Raizada (2011) could show that green fluorescent protein-tagged Enterobacter asburiaes could systemically colonize the roots of maize and even the rhizosphere. This means that some genera of the initial endophytic microbiome may possess the ability to colonize not only the plant roots but also the rhizosphere. In order to have plants which are preinoculated with PGPB that can influence not only the endosphere but also the rhizosphere and, therefore, may be able to reduce the ARD effect, inoculation studies are needed.

Next to differences between the years, variations within the soil variants were observed. The observed ASVs and the different diversity indices within the variants showed high standard deviations (Tables 2 and 3). With the reanalysis of several studies of microbiomes of ARD-affected soils, Nicola et al. (2018) determined that the strongest factor for bacterial community variation were environmental variables. In our study, several factors responsible for variations were reduced to a minimum (soils mixed, clonally propagated plants, and the same greenhouse conditions). However, here, we were investigating the root endophytic community. Its selection is strongly controlled by the host plant and dependent on soil and several other factors such as stress and environmental conditions (Afzal et al. 2019). Although all plants and soils within a variant were treated in the same way, individual differences in the soil microbiome and, therefore, differences in root colonization cannot be excluded. To reduce these variations, future biotests should increase the number of analyzed plants.

Are streptomycetes part of the ARD complex? Our results show that nearly all Streptomyces ASVs were negatively correlated with increase in shoot length and shoot fresh mass (Figs. 2 and 3). Interestingly, the same ASVs were also identified in the roots of the rootstock cultivar Bittenfelder grown in ARD-affected soil in the three reference field sites Heidgraben, Ellerhoop, and Ruthe (results not shown). Therefore, regardless of the year, whether greenhouse biotest or field experiment, the site, or the apple rootstock genotype, Streptomyces ASVs were associated with apple roots grown in ARD soils. This raises the question whether Streptomyces spp. are a causative part of the ARD complex or just opportunistic or secondary colonizers.

Streptomyces is a well-studied genus and most famous for its production of antibiotics, with $80 \%$ of today's antibiotics being derived from Streptomyces spp. (de Lima Procópio et al. 2012). Next to this, traits such as production of antifungal substances and siderophores, solubilization of phosphate, synthesis of plant growth regulators, secretion of volatile compounds, biocontrol (competition for nutrients), and degradation of phytotoxins makes this genus a potent PGPB, intensively reviewed by Olanrewaju and Babalola (2019), Sousa and Olivares (2016), Viaene et al. (2016), and Vurukonda et al. (2018). These reviews also highlight that genus Streptomyces is able to colonize a broad range of plant hosts. It is further believed that these plants can selectively recruit Streptomyces spp. (Viaene et al. 2016). However, the signals which attract them or the way of their entering and colonizing the roots are still unknown (Viaene et al. 2016; Vurukonda et al. 2018).

However, these various plant-growth-promoting effects of Streptomyces were not affirmed by our findings. Roots growing in soil from the grass variants showed better growth than those in ARD soils. Only two Streptomyces ASVs unique for at least two grass variants were found which had no correlation with increase in shoot length and shoot fresh mass (Supplementary Figs. S6 and S7). In contrast, in ARD variants, a clear negative correlation of the relative abundance of Streptomyces spp. and plant growth was shown (Figs. 2 and 3). On the one hand, this could indicate that genus Streptomyces is pathogenic and part of the replant disease. On the other hand, because Streptomyces has a saprophytic lifestyle, it could be an opportunist and degrade dead or damaged root material. Structurally damaged and partially necrotic root systems are typical symptoms for ARD-affected plants (Grunewaldt-Stöcker et al. 2019). Streptomyces spp. are able to break down organic remains of plants using several hydrolytic exoenzymes such as cellulases, lignocellulases, pectinases, xylanases, and cutinases (Chater 2016; Chater et al. 2010). Streptomyces was also shown to appear in higher abundance in the rhizosphere of Arabidopsis thaliana when plant exudated phenolic-related compounds such as salicylic acid were present (Badri et al. 2013; Lebeis et al. 2015) and can even grow on minimal media with only salicylic acid as a carbon source (Lebeis et al. 2015). Due to tyrosinase activity, some isolates were partially protected against plant-produced phenols, leading to increased colonization rates on $A$. thaliana roots (Chewning et al. 2019). Gene expression studies revealed that genes responsible for the production of phytoalexins (some of which belong to polyphenols) are upregulated in M26 roots growing in ARD-affected soils (Weiß et al. 2017a,b).

Overall, these reasons make it seem likely that genus Streptomyces finds favorable conditions and occurs in higher abundance in ARD-affected roots and, hence, is opportunistic. Yet pathogenicity cannot be excluded.

Of the 672 known Streptomyces spp. (Euzéby 1997; Parte 2018) (number as of 3 December 2020), only 10 have pathogenic features (Viaene et al. 2016). Most known are Streptomyces scabies, $S$. acidiscabies, and $S$. turgidiscabies, which cause common scab on roots and tuber crops. These species are able to directly penetrate plant cells and, in addition to necrotic scab lesions, lead to reduced growth, root stunting and browning, and a reduction of the complexity of the root system (Loria et al. 2003, 2006; Seipke et al. 2012) (i.e., symptoms that resemble the phenotype of ARD-affected roots). However, despite the large host range, none of these species were reported to infect woody plants, although the host range likely includes all higher plants, because dicot and monocot seedlings of several plant species have shown symptoms after inoculation with S. scabies (Leiner et al. 1996; Loria et al. 2006). One reason for this large host range is based on the assumption that genus Streptomyces is believed to have originated 400 million years ago, when green plants started to colonize the land (Chater 2016). Another reason for this flexibility is the fact that Streptomyces virulence genes are clustered on a pathogenic island which can be mobilized and, via conjugation, transferred to nonpathogenic relatives, which leads to the emergence of new plant-pathogenic streptomycetes (Lerat et al. 2009).

A closer look at the genus Streptomyces from our greenhouse experiment revealed that the Streptomyces ASVs which occurred in 
at least two sites (Figs. 2 and 3) shared a high similarity with the pathogen $S$. turgidiscabies. Blasting the sequences against the NCBI database (https://www.ncbi.nlm.nih.gov/) showed a similarity of $99.76 \%$ (ASV21 and ASV70), 99.51\% (ASV76), and 99.52\% (ASV621) (Supplementary Table S1). All of these ASVs showed a negative correlation with shoot fresh mass of approximately -0.60 or more, whereas ASV121, which showed the lowest negative correlation of -0.34 also shared the lowest identity with S. turgidiscabies (97.32\%). However, for further comparisons to Streptomyces spp., the complete $16 \mathrm{~S}$ rRNA sequence of the apple root endophytes identified in this study is necessary.

Nevertheless, the high similarity to pathogenic Streptomyces spp., the broad host range, and the ability for horizontal gene transfer of virulence genes may be arguments in favor of genus Streptomyces as a possible causative organism of ARD.

Role of genus Streptomyces in ARD. Several previous studies investigated Streptomyces in relation to ARD. However, they resulted in controversial conclusions. Genus Streptomyces is part of the order of Actinomycetales, members of which were first mentioned as a possible cause of ARD by Otto and Winkler (1977). The authors at that time could only identify the bacteria by their morphology at the level of the phylum, which was called "Actinomycetes" in those days. In their histological analysis, "Actinomycetes" species were found in damaged roots of apple seedlings with a frequency of $47.3 \%$ in replant affected soil but not $(0.3 \%)$ in steamed soil (Otto and Winkler 1977). Also, in plants from our greenhouse experiments, Actinobacteria were histologically observed more frequently in roots in untreated ARD soils than in nonARD soils (Grunewaldt-Stöcker et al. 2019). The so called "rootpathogenic Actinomycetes" (Otto et al. 1993) were observed in ARD-affected roots of apple seedlings. Thereafter, the degree of infestation increased with increasing shoot growth and decreased with stagnating growth. This led to the assumption that root exudates, which are influenced qualitatively and quantitatively by the growing buds, triggered the germination of persistent spores (Otto et al. 1993).

In contrast to a pathogenic role, Streptomyces spp. were considered to be plant growth promoters in other studies dealing with ARD. 16S rRNA pyrosequencing revealed that the genus Streptomyces was positively (0.64) correlated with shoot growth in plants grown in fumigated ARD soil (Nicola et al. 2017). A function in disease suppression was also associated with Streptomyces (Cohen and Mazzola 2006; Cohen et al. 2005; Mazzola et al. 2007), when the effect of seed meal amendments on the putative ARD-causing pathogens Rhizoctonia solani or Pythium spp. was investigated. Seed meal amendments resulted in increased populations of Streptomyces, which were able to suppress infections by $R$. solani. Disease suppression was attributed to a transformation of bacterial community structure and the production of nitric oxide (Cohen and Mazzola 2006; Cohen et al. 2005), which plays a role in the induction of plant systemic resistance. Most Streptomyces isolates recovered from the apple rhizosphere were able to produce nitric oxide (Cohen et al. 2005). By adding any of several Streptomyces strains, Cohen and Mazzola (2006) could restore disease suppressiveness in previously pasteurized soil. Next to disease suppression, promotion of root infection by Streptomyces spp. was also observed in apple (Zhao et al. 2009) and Picea abies (Lehr et al. 2007). Root infections were significantly elevated in the presence of Streptomyces spp. This may be a negative side effect, because genus Streptomyces is known to promote mycorrhizal formation by promoting fungal growth and by decreasing the plant defense response (Lehr et al. 2007; Tarkka et al. 2008; Vurukonda et al. 2018). Streptomyces sp. AcH 505 was shown to downregulate the peroxidase activity and pathogenesis-related peroxidase gene (Spi2) expression (Lehr et al. 2007) of the host plant, thus promoting fungal root colonization.

Furthermore, two more traits of genus Streptomyces match the characteristics of ARD. First, like ARD, Streptomyces can persist for a very long time in soil. Due to no or minimal metabolic activity, spores can survive harsh conditions for years (Bobek et al. 2017). Second, Streptomyces is very sensitive to waterlogged conditions. Streptomyces is more abundant in drained soils (sandy loam) than in heavy soils (Gowdar et al. 2018) and, similarly, ARD is usually more severe in light soil compared with heavy soils (Mahnkopp et al. 2018; Winkelmann et al. 2019).

All of these findings indicate that Streptomyces spp. could be responsible for ARD or be part of it. However, to prove this, inoculation experiments are necessary, as was done by Tewoldemedhin et al. (2011). They isolated 92 Streptomyces strains from surfacesterilized roots from six ARD-affected sites in South Africa and inoculated 37 of them to 4-week-old apple seedlings to test pathogenicity. Moreover, 11 were coinoculated with the pathogens Pythium irregulare and C. macrodidymum. All tested streptomycetes had no effect on plant growth. At first, this seems to be a clear sign that these Streptomyces isolates were not pathogenic (directly or indirectly). However, these isolates had low identity (less than 98\%) to known Streptomyces spp. and none showed close similarity to S. turgidiscabies, which had a high identity to our ASVs, with a negative correlation with plant growth. Also, in our experiments, not all Streptomyces spp. were negatively correlated with plant growth. In 2017, of 61 detected ASVs, only 6 showed negative correlations with shoot fresh mass (15 of 32 in 2016). Furthermore, inoculation trials were done in artificial soil (bark medium and sand [2:1]) (Tewoldemedhin et al. 2011), which means that potential "copathogens" were not present, unlike in ARD soil.

Streptomyces not present in T0 plants. Only very few of the detected ASVs assigned to genus Streptomyces negatively linked to plant growth were present in T0 plants (data not shown). In 2017, only Streptomyces ASV611 was present in one of four replicates with a relative abundance of $0.38 \%$. In 2016, ASV121 was detected in three of four replicates, one with a relative abundance of $1.39 \%$. All other Streptomyces ASVs were not present in T0 plants. Because genus Streptomyces is widely distributed in soils (Ferrer et al. 2018; Olanrewaju and Babalola 2019; Seipke et al. 2012), plants in our experiments were most likely colonized after planting in the different soil variants. Based on molecular fingerprints of rhizosphere and bulk soil, Lucas et al. (2018) confirmed that Streptomyces is more abundant in ARD compared with grass control soil.

PGPB in plants grown in non-ARD soils. In order to find possible PGPB that may be used to overcome ARD, we also looked at the unique ASVs in the grass variants to find ASVs positively correlated with plant growth. However, in 2016, no ASV showed any significant positive correlation (Supplementary Fig. S6). In 2017, only one ASV (NA_ASV4691 [Rhizobiaceae]) showed a positive correlation with an increase in shoot length and shoot fresh mass, with 0.32 and 0.30 , respectively.

Conclusion. Here, we showed, for the first time, the apple root endophytic community composition in plants grown on three replant-affected soils in comparison with non-replant-affected soils based on next-generation sequencing in 2 years. Although no PGPB to counteract ARD could be found, several ASVs with negative correlations with plant growth were associated with ARD. With Streptomyces spp. showing strong negative correlations and being present in all soils over the years, a potential key player for the cause of ARD may have been found. However, it remains to be clarified in future studies whether genus Streptomyces as root endophyte in ARD situations acts opportunistically or is pathogenic. Streptomyces spp. can grow saprophytically and just degrade plant material 
and metabolize plant exudates; however, they can also play an essential role in the ARD complex by suppressing plant defense responses and, thereby, promote infection of fungal pathogens. Further inoculation studies with Streptomyces isolates in combination with fungal pathogens as coinoculants will help to answer this question.

\section{ACKNOWLEDGMENTS}

We thank several colleagues and students at Leibniz Universität Hannover, especially E. Schneider and C. Popp, for their help; and B. Fösel from Helmholtz Center Munich for providing microbiomeassociated next-generation sequencing service and proofreading the manuscript.

\section{LITERATURE CITED}

Afzal, I., Shinwari, Z. K., Sikandar, S., and Shahzad, S. 2019. Plant beneficial endophytic bacteria: Mechanisms, diversity, host range and genetic determinants. Microbiol. Res. 221:36-49.

Badri, D. V., Chaparro, J. M., Zhang, R., Shen, Q., and Vivanco, J. M. 2013. Application of natural blends of phytochemicals derived from the root exudates of Arabidopsis to the soil reveal that phenolic-related compounds predominantly modulate the soil microbiome. J. Biol. Chem. 288:4502-4512.

Berg, G., and Smalla, K. 2009. Plant species and soil type cooperatively shape the structure and function of microbial communities in the rhizosphere. FEMS Microbiol. Ecol. 68:1-13.

Bobek, J., Smídová, K., and Cihák, M. 2017. A waking review: Old and novel insights into the spore germination in Streptomyces. Front. Microbiol. $8: 2205$.

Bonito, G., Reynolds, H., Robeson, M. S., Nelson, J., Hodkinson, B. P., Tuskan, G., Schadt, C. W., and Vilgalys, R. 2014. Plant host and soil origin influence fungal and bacterial assemblages in the roots of woody plants. Mol. Ecol. 23: 3356-3370.

Bulgarelli, D., Schlaeppi, K., Spaepen, S., Van Themaat, E. V. L., and SchulzeLefert, P. 2013. Structure and functions of the bacterial microbiota of plants. Annu. Rev. Plant Biol. 64:807-838.

Callahan, B. J., McMurdie, P. J., Rosen, M. J., Han, A. W., Johnson, A. J. A., and Holmes, S. P. 2016. DADA2: High-resolution sample inference from Illumina amplicon data. Nat. Methods 13:581-583.

Caporaso, J. G., Kuczynski, J., Stombaugh, J., Bittinger, K., Bushman, F. D., Costello, E. K., Fierer, N., Peña, A. G., Goodrich, J. K., Gordon, J. I., Huttley, G. A., Kelley, S. T., Knights, D., Koenig, J. E., Ley, R. E., Lozupone, C. A., McDonald, D., Muegge, B. D., Pirrung, M., Reder, J., Sevinsky, J. R., Turnbaugh, P. J., Walters, W. A., Widmann, J., Yatsunenko, T., Zaneveld, J., and Knight, R. 2010. QIIME allows analysis of high-throughput community sequencing data. Nat. Methods 7:335-336.

Čatská, V., Vančura, V., Hudská, G., and Přikryl, Z. 1982. Rhizosphere microorganisms in relation to the apple replant problem. Plant Soil 69:187-197.

Chater, K. F. 2016. Recent advances in understanding Streptomyces. F1000 Res. $5: 2795$.

Chater, K. F., Biró, S., Lee, K. J., Palmer, T., and Schrempf, H. 2010. The complex extracellular biology of Streptomyces. FEMS Microbiol. Rev. 34: 171-198.

Chewning, S., Grant, D., O’Banion, B., Gates, A., Kennedy, B., Campagna, S., and Lebeis, S. 2019. Root-associated Streptomyces isolates harboring melC genes demonstrate enhanced plant colonization. Phytobiomes J. 3:165-176.

Cohen, M. F., and Mazzola, M. 2006. Resident bacteria, nitric oxide emission and particle size modulate the effect of Brassica napus seed meal on disease incited by Rhizoctonia solani and Pythium spp. Plant Soil 286:75-86.

Cohen, M. F., Yamasaki, H., and Mazzola, M. 2005. Brassica napus seed meal soil amendment modifies microbial community structure, nitric oxide production and incidence of Rhizoctonia root rot. Soil Biol. Biochem. 37:1215-1227.

de Lima Procópio, R. E., Da Silva, I. R., Martins, M. K., De Azevedo, J. L., and De Araújo, J. M. 2012. Antibiotics produced by Streptomyces. Braz. J. Infect. Dis. 16:466-471.

Dorn-In, S., Bassitta, R., Schwaiger, K., Bauer, J., and Hölzel, C. S. 2015. Specific amplification of bacterial DNA by optimized so-called universal bacterial primers in samples rich of plant DNA. Microbiol Methods 113: 50-56.
Euzéby, J. P. 1997. List of bacterial names with standing in nomenclature: A folder available on the Internet. Int. J. Syst. Bacteriol. 47:590-592.

Ferrer, C., Olivete, E., Orias, S., Rocas, M., Juan, S., Dungca, J., Mahboob, T., Barusrux, S., and Nissapatorn, V. 2018. A review on Streptomyces spp. as plant-growth promoting bacteria (PGPB). Asian J. Pharmacogn. 2:32-40.

Franke-Whittle, I. H., Manici, L. M., Insam, H., and Stres, B. 2015. Rhizosphere bacteria and fungi associated with plant growth in soils of three replanted apple orchards. Plant Soil 395:317-333.

Gaiero, J. R., McCall, C. A., Thompson, K. A., Day, N. J., Best, A. S., and Dunfield, K. E. 2013. Inside the root microbiome: Bacterial root endophytes and plant growth promotion. Am. J. Bot. 100:1738-1750.

Gowdar, S. B., Deepa, H. and Amaresh, Y. S. 2018. A brief review on biocontrol potential and PGPR traits of Streptomyces sp. for the management of plant diseases. J. Pharmacogn. Phytochem. 7:03-07.

Grunewaldt-Stöcker, G., Mahnkopp, F., Popp, C., Maiss, E., and Winkelmann, T. 2019. Diagnosis of apple replant disease (ARD): Microscopic evidence of early symptoms in fine roots of different apple rootstock genotypes. Sci. Hortic. (Amsterdam) 243:583-594.

Haas, D., and Keel, C. 2003. Regulation of antibiotic production in rootcolonizing Pseudomonas spp. and relevance for biological control of plant disease. Annu. Rev. Phytopathol. 41:117-153.

Hall, T. A. 1999. BioEdit: A user-friendly biological sequence alignment editor and analysis program for Windows 95/98/NT. Nucleic Acids Symp. Ser. 41: 95-98.

Hammer, Ø., Harper, D. A. T., and Ryan, P. D. 2001. PAST: Paleontological statistics software package for education and data analysis. Palaeontol. Electron. 4:9.

Hardoim, P. R., Van Overbeek, L. S., Berg, G., Pirttilä, A. M., Compant, S., Campisano, A., Döring, M., and Sessitsch, A. 2015. The hidden world within plants: Ecological and evolutionary considerations for defining functioning of microbial endophytes. Microbiol. Mol. Biol. Rev. 79:293-320.

Hardoim, P. R., Van Overbeek, L. S., and Elsas, J. D. 2008. Properties of bacterial endophytes and their proposed role in plant growth. Trends Microbiol. 16:463-471.

Hartman, K., and Tringe, S. G. 2019. Interactions between plants and soil shaping the root microbiome under abiotic stress. Biochem. J. 476: 2705-2724.

Herberich, E., Sikorski, J., and Hothorn, T. 2010. A robust procedure for comparing multiple means under heteroscedasticity in unbalanced designs. PLoS One 5:e9788.

Johnston-Monje, D., and Raizada, M. N. 2011. Conservation and diversity of seed associated endophytes in Zea across boundaries of evolution, ethnography and ecology. PLoS One 6:e20396.

Kelderer, M., Manici, L. M., Caputo, F., and Thalheimer, M. 2012. Planting in the 'inter-row' to overcome replant disease in apple orchards: A study on the effectiveness of the practice based on microbial indicators. Plant Soil 357: 381-393.

Lareen, A., Burton, F., and Schäfer, P. 2016. Plant root-microbe communication in shaping root microbiomes. Plant Mol. Biol. 90:575-587.

Lebeis, S. L., Paredes, S. H., Lundberg, D. S., Breakfield, N., Gehring, J., McDonald, M., Malfatti, S., Del Rio, T. G., Jones, C. D., Tringe, S. G., and Dangl, J. L. 2015. Salicylic acid modulates colonization of the root microbiome by specific bacterial taxa. Science 349:860-864.

Lehr, N. A., Schrey, S. D., Bauer, R., Hampp, R., and Tarkka, M. T. 2007. Suppression of plant defence response by a mycorrhiza helper bacterium. New Phytol. 174:892-903.

Leiner, R. H., Fry, B. A., Carling, D. E., and Loria, R. 1996. Probable involvement of thaxtomin A in pathogenicity of Streptomyces scabies on seedlings. Phytopathology 86:709-713.

Lerat, S., Simao-Beaunoir, A. M., and Beaulieu, C. 2009. Genetic and physiological determinants of Streptomyces scabies pathogenicity. Mol. Plant Pathol. 10:579-585.

Levene, H. 1960. Robust tests for equality of variances. Pages 278-292 in: Contributions to Probability and Statistics: Essays in Honor of Harold Hotelling. I. Olkin, S. G. Ghurye, W. Hoeffding, W. G. Madow, and H. B. Mann, eds. Stanford University Press, Palo Alto, CA.

Loria, R., Coombs, J., Yoshida, M., Kers, J. and Bukhalid, R. 2003. A paucity of bacterial root diseases: Streptomyces succeeds where others fail. Physiol. Mol. Plant Pathol. 62:65-72.

Loria, R., Kers, J., and Joshi, M. 2006. Evolution of plant pathogenicity in Streptomyces. Annu. Rev. Phytopathol. 44:469-487.

Lucas, M., Balbin-Suarez, A., Smalla, K., and Vetterlein, D. 2018. Root growth, function and rhizosphere microbiome analyses show local rather than 
systemic effects in apple plant response to replant disease soil. PLoS One 13: $\mathrm{e} 0204922$.

Lundberg, D. S., Lebeis, S. L., Paredes, S. H., Yourstone, S., Gehring, J., Malfatti, S., Tremblay, J., Engelbrektson, A., Kunin, V., Del Rio, T. G., Edgar, R. C., Eickhorst, T., Ley, R. E., Hugenholtz, P., Tringe, S. G., and Dangl, J. L. 2012. Defining the core Arabidopsis thaliana root microbiome. Nature 488:86-90.

Mahnkopp, F., Simon, M., Lehndorff, E., Pätzold, S., Wrede, A., and Winkelmann, T. 2018. Induction and diagnosis of apple replant disease (ARD): A matter of heterogeneous soil properties? Sci. Hortic. (Amsterdam) 241:167-177.

Mai, W. F., and Abawi, G. S. 1981. Controlling replant disease of stone fruits in northeastern United States by preplant fumigation. Plant Dis. 65: 859-864.

Manici, L. M., Caputo, F., and Saccà, M. L. 2017. Secondary metabolites released into the rhizosphere by Fusarium oxysporum and Fusarium spp. as underestimated component of nonspecific replant disease. Plant Soil 415: 217-230.

Manici, L. M., Kelderer, M., Franke-Whittle, I. H., Rühmer, T., Baab, G., Nicoletti, F., Caputo, F., Topp, A. R., Insam, H., and Naef, A. 2013. Relationship between root-endophytic microbial communities and replant disease in specialized apple growing areas in Europe. Appl. Soil Ecol. 72: 207-214.

Mazzola, M. 1998. Elucidation of the microbial complex having a causal role in the development of apple replant disease in Washington. Phytopathology 88: 930-938.

Mazzola, M., Brown, J., Izzo, A. D., and Cohen, M. F. 2007. Mechanism of action and efficacy of seed meal-induced pathogen suppression differ in a Brassicaceae species and time-dependent manner. Phytopathology 97: 454-460.

Mazzola, M., and Manici, L. M. 2012. Apple replant disease: Role of microbial ecology in cause and control. Annu. Rev. Phytopathol. 50:45-65.

McMurdie, P. J., and Holmes, S. 2013. phyloseq: An R package for reproducible interactive analysis and graphics of microbiome census data. PLoS One 8: e61217.

Nicola, L., Insam, H., Pertot, I., and Stres, B. 2018. Reanalysis of microbiomes in soils affected by apple replant disease (ARD): Old foes and novel suspects lead to the proposal of extended model of disease development. Appl. Soil Ecol. 129:24-33.

Nicola, L., Turco, E., Albanese, D., Donati, C., Thalheimer, M., Pindo, M., Insam, H., Cavalieri, D., and Pertot, I. 2017. Fumigation with dazomet modifies soil microbiota in apple orchards affected by replant disease. Appl. Soil Ecol. 113:71-79.

Oksanen, J. F., Blanchet, G., Friendly, M., Kindt, R., Legendre, P., McGlinn, D., Minchin, P. R., O’Hara, R. B., Simpson, G. L., Solymos, P., Stevens, M. H. H., Szoecs, E., and Wagner, H. 2019. vegan: Community Ecology Package. R package version 2.5-6. https://cran.r-project.org/web/packages/vegan/ index.html

Olanrewaju, O. S., and Babalola, O. O. 2019. Streptomyces: Implications and interactions in plant growth promotion. Appl. Microbiol. Biotechnol. 103: 1179-1188.

Orozco-Mosqueda, M. D. C., Rocha-Granados, M. D. C., Glick, B. R., and Santoyo, G. 2018. Microbiome engineering to improve biocontrol and plant growth-promoting mechanisms. Microbiol. Res. 208:25-31.

Otto, G., and Winkler, H. 1977. Untersuchungen über die Ursache der Bodenmüdigkeit bei Obstgehölzen. VI. Nachweis von Aktinomyzeten in Faserwurzeln von Apfelsämlingen in Böden mit verschiedenen Müdigkeitsgraden. Zentralbl. Bakteriol., Parasitenkd., Infektionskrankh. Hyg. Abt. II. 132:593-606.

Otto, G., and Winkler, H. 1993. Colonization of rootlets of apple seedlings from replant soil by actinomycetes and endotrophic mycorrhiza. Acta Hortic. 324: 53-60.

Otto, G., Winkler, H., and Szabó, K. 1993. Untersuchungen zum Verlauf des Befalls der Faserwurzeln von Apfelsämlingen durch wurzelpathogene Aktinomyzeten in apfelmüden Böden [Investigations about the course of infestation of rootlets of apple seedlings by root pathogenic actinomycetes in soils with specific apple replant disease]. Zentralbl. Mikrobiol. 148: 467-476.

Parte, A. C. 2018. LPSN-List of prokaryotic names with standing in nomenclature (bacterio.net), 20 years on. Int. J. Syst. Evol. Microbiol. 68: 1825-1829.

Peruzzi, E., Franke-Whittle, I. H., Kelderer, M., Ciavatta, C., and Insam, H. 2017. Microbial indication of soil health in apple orchards affected by replant disease. Appl. Soil Ecol. 119:115-127.
Popp, C., Grunewaldt-Stöcker, G., and Maiss, E. 2019. A soil-free method for assessing pathogenicity of fungal isolates from apple roots. J. Plant Dis. Prot. 126:329-341.

Preston, G. M., Studholme, D. J., and Caldelari, I. 2005. Profiling the secretomes of plant pathogenic Proteobacteria. FEMS Microbiol. Rev. 29: 331-360.

Radl, V., Winkler, J. B., Kublik, S., Yang, L., Winkelmann, T., Vestergaard, G., Schröder, P., and Schloter, M. 2019. Reduced microbial potential for the degradation of phenolic compounds in the rhizosphere of apple plantlets grown in soils affected by replant disease. Environ. Microbiol. 14:8.

R Development Core Team. 2019. R: A Language and Environment for Statistical Computing. R Foundation for Statistical Computing, Vienna, Austria. http://www.R-project.org

Reinhold-Hurek, B., Bünger, W., Burbano, C. S., Sabale, M., and Hurek, T. 2015. Roots shaping their microbiome: Global hotspots for microbial activity. Annu. Rev. Phytopathol. 53:403-424.

Rosenblueth, M., and Martínez-Romero, E. 2006. Bacterial endophytes and their interactions with hosts. Mol. Plant-Microbe Interact. 19:827-837.

Rumberger, A., Merwin, I. A., and Thies, J. E. 2007. Microbial community development in the rhizosphere of apple trees at a replant disease site. Soil Biol. Biochem. 39:1645-1654.

Santoyo, G., Moreno-Hagelsieb, G., Orozco-Mosqueda, M. D. C., and Glick, B. R. 2016. Plant growth-promoting bacterial endophytes. Microbiol. Res. 183: 92-99.

Savory, B. M. 1966. Specific Replant Diseases Causing Root Necrosis and Growth Depression in Perennial Fruit and Plantation Crops. Research Review No. 1. Commonwealth Bureau of Horticulture and Plantation Crops, East Malling, Maidstone, Kent, England.

Schubert, M., Lindgreen, S., and Orlando, L. 2016. AdapterRemoval v2: Rapid adapter trimming, identification, and read merging. BMC Res. Notes 9:88.

Schulz, B., and Boyle, C. 2005. The endophytic continuum. Mycol. Res. 109: 661-686.

Seipke, R. F., Kaltenpoth, M., and Hutchings, M. I. 2012. Streptomyces as symbionts: An emerging and widespread theme? FEMS Microbiol. Rev. 36: 862-876.

Shapiro, S. S., and Wilk, M. B. 1965. An analysis of variance test for normality (complete samples). Biometrika 52:591-611.

Simon, M., Lehndorff, E., Wrede, A., and Amelung, W. 2020. In-field heterogeneity of apple replant disease: Relations to abiotic soil properties. Sci. Hortic. (Amsterdam) 259:108809.

Sousa, J. A. J., and Olivares, F. L. 2016. Plant growth promotion by streptomycetes: Ecophysiology, mechanisms and applications. Chem. Biol. Technol. Agric. 3:24.

Sun, J., Zhang, Q., Zhou, J., and Wei, Q. 2014. Illumina amplicon sequencing of $16 \mathrm{~S}$ rRNA tag reveals bacterial community development in the rhizosphere of apple nurseries at a replant disease site and a new planting site. PLoS One 9: e111744.

Tarkka, M. T., Lehr, N. A., Hampp, R., and Schrey, S. D. 2008. Plant behavior upon contact with Streptomycetes. Plant Signal. Behav. 3: 917-919.

Tewoldemedhin, Y. T., Mazzola, M., Labuschagne, I., and McLeod, A. 2011. A multi-phasic approach reveals that apple replant disease is caused by multiple biological agents, with some agents acting synergistically. Soil Biol. Biochem. 43:1917-1927.

Thompson, J. D., Higgins, D. G., and Gibson, T. J. 1994. CLUSTAL W: Improving the sensitivity of progressive multiple sequence alignment through sequence weighting, position-specific gap penalties and weight matrix choice. Nucleic Acids Res. 22:4673-4680.

Tilston, E. L., Deakin, G., Bennett, J., Passey, T., Harrison, N., O’Brien, F., Fernández-Fernández, F., and Xu, X. 2018. Candidate causal organisms for apple replant disease in the UK. Phytobiomes J. 2:261-274.

Utkhede, R. S., and Li, T. S. C. 1988. The role of fungi, bacteria, and their interactions in apple replant disease complex in soils of British Columbia. Acta Hortic. 233:75-80.

Viaene, T., Langendries, S., Beirinckx, S., Maes, M., and Goormachtig, S. 2016. Streptomyces as a plant's best friend? FEMS Microbiol. Ecol. 92:fiw119.

Viss, P., Brooks, E., and Driver, J. 1991. A simplified method for the control of bacterial contamination in woody plant tissue culture. In Vitro Cell. Dev. Biol. 27:42.

Vurukonda, S., Giovanardi, D., and Stefani, E. 2018. Plant growth promoting and biocontrol activity of Streptomyces spp. as endophytes. Int. J. Mol. Sci. 19:952.

Weiß, S., Bartsch, M., and Winkelmann, T. 2017a. Transcriptomic analysis of molecular responses in Malus domestica 'M26' roots affected by apple replant disease. Plant Mol. Biol. 94:303-318. 
Weiß, S., Liu, B., Reckwell, D., Beerhues, L., and Winkelmann, T. 2017b. Impaired defense reactions in apple replant disease-affected roots of Malus domestica 'M26'. Tree Physiol. 37:1672-1685.

White, J. F., Kingsley, K. L., Zhang, Q., Verma, R., Obi, N., Dvinskikh, S., Elmore, M. T., Verma, S. K., Surendra, K. G., and Kowalski, K. P. 2019. Review: Endophytic microbes and their potential applications in crop management. Pest Manage. Sci. 75:2558-2565.

Winkelmann, T., Smalla, K., Amelung, W., Baab, G., Grunewaldt-Stöcker, G., Kanfra, X., Meyhöfer, R., Reim, S., Schmitz, M., Vetterlein, D., Wrede, A., Zühlke, S., Grunewaldt, J., Weiß, S., and Schloter, M. 2019. Apple replant disease: Causes and mitigation strategies. Curr. Issues Mol. Biol. 30:89-106.
Yim, B., Smalla, K., and Winkelmann, T. 2013. Evaluation of apple replant problems based on different soil disinfection treatments-links to soil microbial community structure? Plant Soil 366:617-631.

Yim, B., Winkelmann, T., Ding, G. C., and Smalla, K. 2015. Different bacterial communities in heat and gamma irradiation treated replant disease soils revealed by $16 \mathrm{~S}$ rRNA gene analysis-Contribution to improved aboveground apple plant growth? Front. Microbiol. 6:1224.

Zhao, X., Tewoldemedhin, Y., Mcleod, A., and Mazzola, M. 2009. Multiple personalities of Streptomyces spp. isolated from the rhizosphere of apple cultivated in brassica seed meal amended soils. (Abstr.) Phytopathology 99: S150. 